\title{
Simulation and Optimization of Back Pressure Control for Circulating Fluidized Bed Boiler Unit with Unity of Three Towers
}

\author{
ZHANG Li Xiang ${ }^{1, a}$, ZHAO Wei Bin ${ }^{1, b}$, JIAO Yong Bin ${ }^{2, c}$ \\ ${ }^{1}$ Department of automation, Shanxi University, Taiyuan, Shanxi, 030013, China \\ ${ }^{2}$ Shanxi Yuguang Power Generation Co. Ltd. Shanyin, Shanxi, 036900, China \\ a876957442@qq.com, bzwb65@163.com, '632933150@qq.com
}

\begin{abstract}
Keywords: Unity of three towers; Back pressure control; Fuzzy PI control; Smith predictive compensation control; MATLAB simulation;
\end{abstract}

\begin{abstract}
Unity of three towers (i.e. indirect air cooling tower, a desulfurizing tower and a chimney) technology with energy saving and environmental protection, saving water and electricity, high heat efficiency characteristics and a range of promotion and application in coal - fired power generation, and achieved good economic and social benefits. Research and improvement of three in one automatic control technology, to ensure the safety and stability of units to improve the thermal efficiency is particularly important. combined with the use of a certain power plant in Shanxi Province three towers and technical operation of the unit, working state by indirect air cooling system for the unit back pressure is analyzed, the application of fuzzy PI-Smith predictor integrated control strategy, on the back pressure turbine automatic control system simulation and optimization. The results show that the stability and robustness of the system better; the adaptability to load change has achieved good control effect.
\end{abstract}

\section{Introduction}

Shanxi province has huge coal reserves, long-term mining has caused serious environmental pollution, the water level decreased significantly, water resources is becoming increasingly serious problem. At present, the number of direct air cooling units and the system power consumption is much higher, affected by the environment wind is big, fan group will also cause noise pollution. Three towers in one technology as water-saving, low noise, economic type coal-fired power generation new way, so rich in coal but short of water area to improve the environment and sustainable development produced an important role. Therefore, the research and improvement of three towers in one technology, it is necessary for Shanxi province electric power and environmental transformation and leapfrog development. "Three towers in one" is the coal-fired power plant indirect air cooling towers, chimneys, and desulfurization absorption tower together in one, the tail flue gas pipeline through the air cooling tower wall into the arrangement in air cooling tower center of desulfurization absorption tower, after the desulfurization treatment, utilize ascending flue gas discharged force air cooling tower, desulfurization absorption tower, exhaust pump, slurry circulating pump, an oxidation wind machine and equipment layout in the cooling tower of the coal-fired power plant system optimization technology layout. one of Shanxi circulating fluidized bed power plant adopts three tower technology, two units sharing a natural ventilation cooling tower, a chimney, two desulfurization absorption tower arrangement in natural ventilation tower, the mixed condensation type condenser indirect air cooling system (i.e. Heller type indirect air cooling system).

Heller system as shown in Fig.1, mainly by the jet condenser and air cooling tower. In the system, neutral cooling water into the condenser directly mixed with steam turbine exhaust steam and condensate, heated by water circulating pump of cooling water radiator, sent to the cooling tower and cooling air convection in the cooling water by regulating water turbine after then sent to the jet condenser into the next cycle. At the same time, due to the three towers together system structure of complex equipment , system is affected by many factors, such as a unit load, ambient temperature, the temperature of the circulating water, environmental wind speed are on the operation stability of 
the whole system has a very important influence. In the operation of many units, mostly adopts the conventional PID control, but rarely put to run automatically. In this paper, based on advanced control theory, fuzzy PI - Smith forecast compensation control strategy, and in view of the back pressure control system design and simulation research. According to advanced control theory, this paper proposes a control strategy based on fuzzy PI-Smith predictor, and designs a system for the control of unit back pressure.

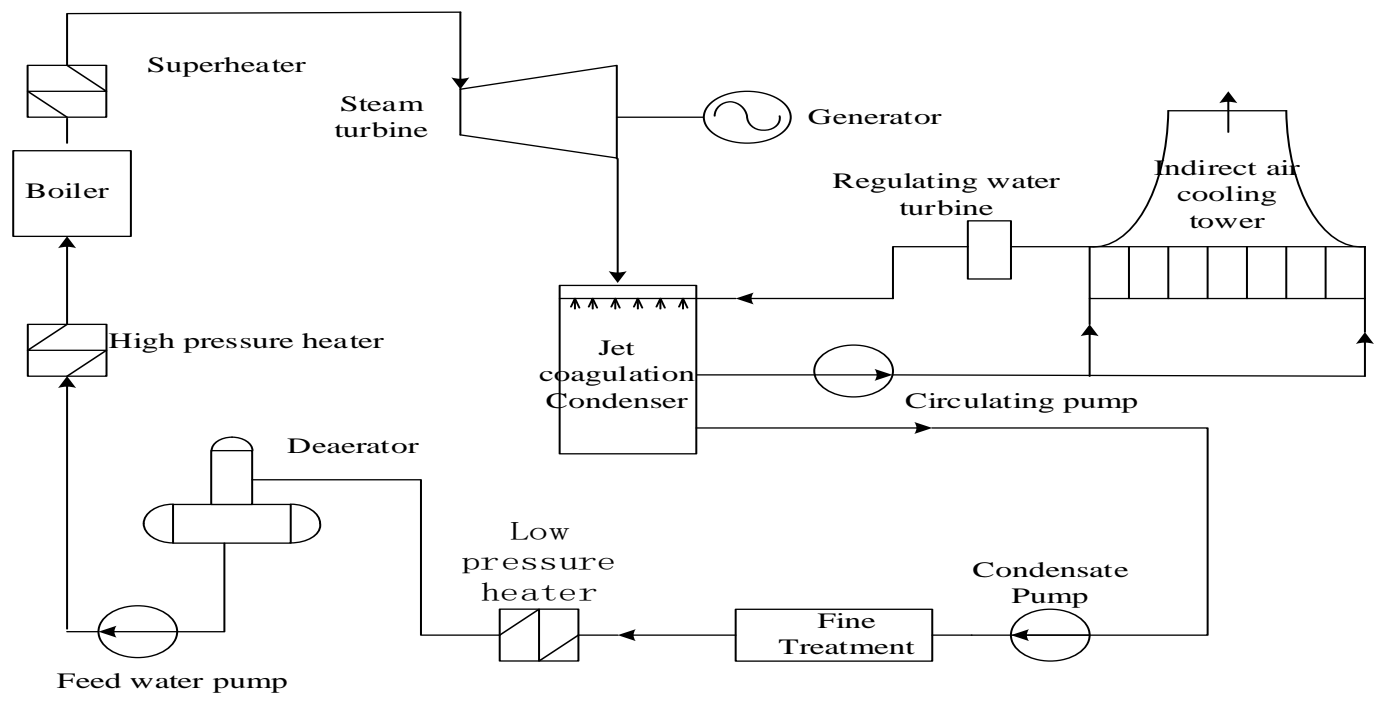

Fig. 1 Heller type indirect air cooling system

\section{Fuzzy PI-Smith predictive control system design}

Fuzzy PI-Smith predictive control theory. Fuzzy PI-Smith predictor compensation control method is very effective for nonlinear, large delay and large inertia objects, as shown in Fig. 2. Its characteristic is to estimate the dynamic characteristics of the controlled process, and then to estimate the compensation, so that the process of pure delays in the process of the closed-loop system, and the controller in a timely manner, so as to effectively reduce the overshoot and improve the control performance.

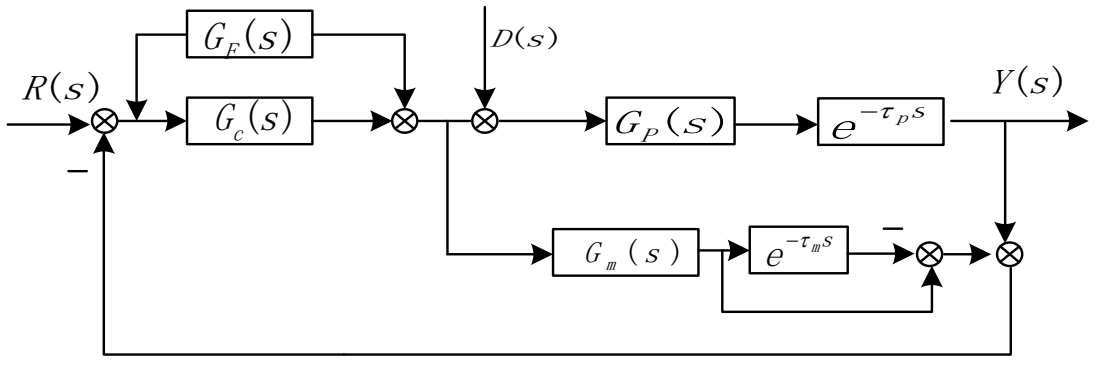

Fig. 2 Fuzzy PI-Smith fuzzy predictive control theory

When the model is accurate, that is $G_{p}(s) e^{-\tau_{p} s}=G_{m}(s) e^{-\tau_{m} s}$, the closed loop transfer function of the compensated Smith is:

$$
\frac{Y(s)}{R(s)}=\frac{\left(G_{c}(s)+G_{F}(s)\right) G_{p}(s) e^{-\tau_{p} s}}{1+\left(G_{c}(s)+G_{F}(s)\right) G_{p}(s)} .
$$

At this point, the system's characteristic equation has not included $e^{-\tau s}$, the effect of the delay on the control quality of the system has been eliminated, Just the response to the time coordinate, which has been delayed for the time of $e^{-\tau S}$. 
Fuzzy control does not need accurate mathematical model, its robustness is strong, and it has strong fault tolerance ability. It is suitable for the object of nonlinear, strong coupling, delay, etc. The fuzzy PI controller is used in the system, and the advantages of fuzzy control and PI control are combined. $G_{F}(s)$ adopts Two dimensional fuzzy controller, To the unit back pressure deviation and the deviation change rate as the input of the controller, Combined with PID to eliminate static error, to achieve the effect of stability control. The fuzzy rules are determined by the experience and the specific technical requirements of the operating personnel, when the unit back pressure is too high, to increase the shutter opening. When the back pressure changes greatly, reduce the back pressure deviation as soon as possible, when the back pressure change is small, pay attention to prevent overshoot and guarantee the system stability.

Turbine back pressure automatic control design. Back pressure refers to the steam turbine exhaust steam pressure, when the environment temperature is lower; the higher of the turbine vacuum, the turbine back pressure is lower. On the contrary, the higher the temperature, the lower vacuum of unit, the higher back pressure steam turbine. Turbine running in the summer, due to environment temperature on the high side, so it is particularly important to the turbine back pressure control. The automatic control SAMA diagram as shown in Fig.3.

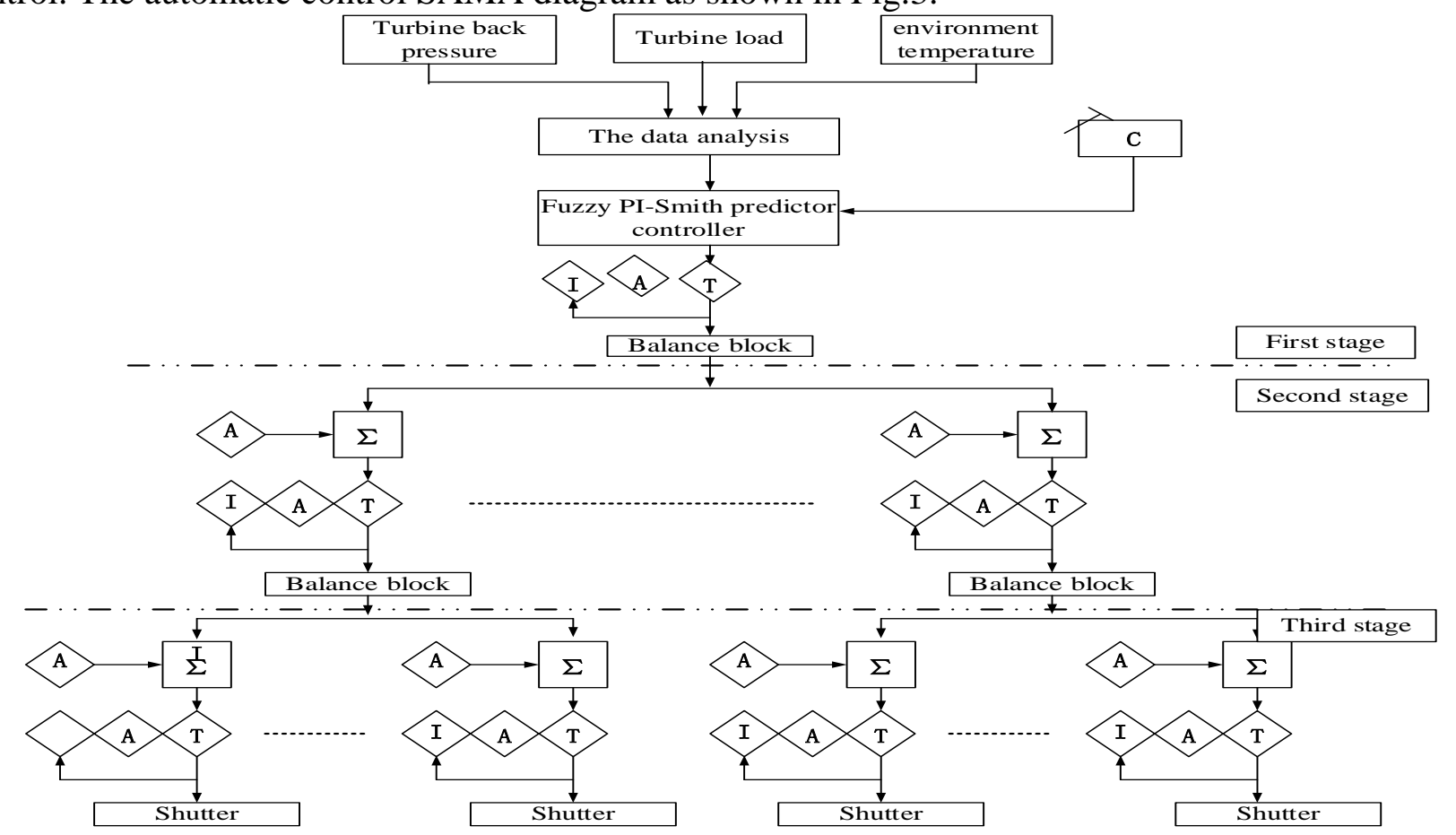

Fig.3 Automatic control of shutter opening

Unit adopts the three pagodas technology, its indirect air cooling system cooling triangle on the inlet side installed shutters, by partially closed shutters can reduce the cooling capacity of the cooling tower. Cooling the summer back pressure control by changing the Heller type indirect air cooling system shutter opening to change the natural ventilation cooling tower air through flow area, control the temperature of the cooling water, so as to realize the turbine backpressure is stable within the allowed range.

\section{Simulation study on back pressure control of steam turbine}

Study on the characteristics of steam turbine back pressure. According to the running experience and operation data of a power plant of Shanxi which adopts three towers in one unit technology, we can fit the running curve. When the rated power of the unit is 300MW, the steam pressure rating of the steam turbine is $26 \mathrm{KPa}$, According to operation, the ambient temperature of $15^{\circ} \mathrm{C}$, when the load is $213 \mathrm{MW}$, we will shutter opening fell to $89 \%$ from $17 \%$, the change of back pressure as shown in Fig. 4. 


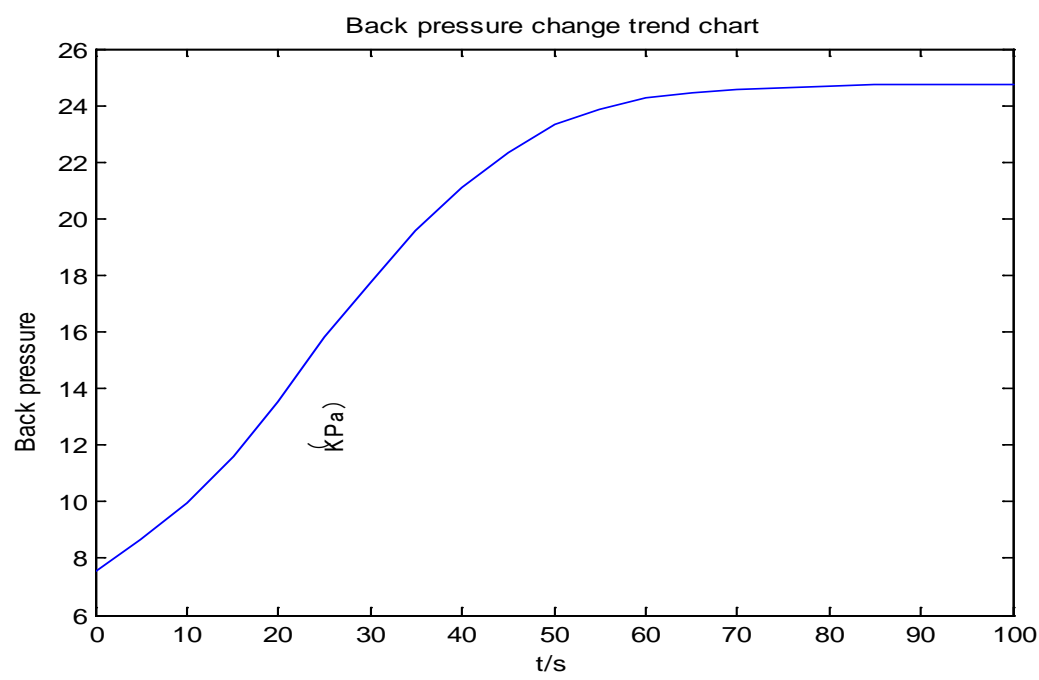

Fig.4 back pressure change trend chart

Turbine back pressure control is through the change of cooling the inlet side of the shutter opening triangle, to provide the proper cooling air flow rate, cooling water temperature decrease, so as to change the back pressure. According to the operation experience and data from the field, we can use it as a first-order system with time delay, the equivalent model is set up as follows:

$$
\mathrm{G}_{\mathrm{p}}(S)=\frac{K_{P}}{T_{P} S+1} e^{-\tau_{p} S} .
$$

Through MATLAB curve fitting, get the system transfer function is:

$$
\mathrm{G}_{\mathrm{p}}(s)=\frac{26.801}{32.485 s+1} e^{-6.644 s} \text {. }
$$

We used the same method, can be solved under $298 \mathrm{MW}$ and 152MW load transfer function is:

$$
\begin{aligned}
& \mathrm{G}_{\mathrm{p}}(s)=\frac{36.249}{59.374 s+1} e^{-9.7344 s} . \\
& \mathrm{G}_{\mathrm{p}}(s)=\frac{31.547}{46.583 s+1} e^{-7.985 s} .
\end{aligned}
$$

System simulation analysis. We through MATLAB Simulink simulation model are established. According to the power plant operation data, run back pressure is generally between $5.73 \mathrm{KPa}$ -27.89 KPa, we so choose step response as the system input signal.

We adopt fuzzy PI - Smith forecast compensation controller and Simulink toolbox in MATLAB to carry on the design and application, after the parameters setting, system under the $213 \mathrm{mw}$ load, two kinds of control strategies contrast diagram is shown in fig.5. 


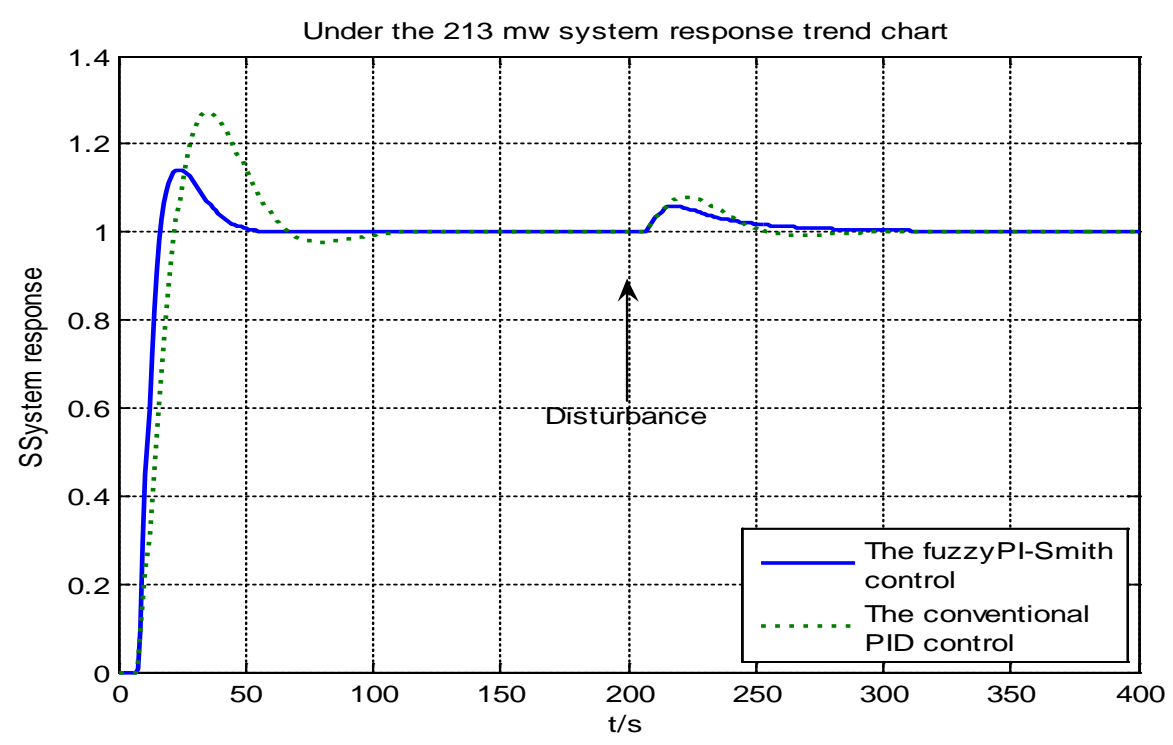

Fig.5 comparison chart of two control strategies under 213MW load

We analyze and compare the responses of two different control strategies in Fig. 5. The PI-Smith control strategy is faster than conventional PID control system, and the overshoot is smaller, the stability time is shorter, the back pressure of the unit can be more quickly followed by the change of the load and make a quick response, while in the anti - jamming, also has its certain advantages.

Under different load conditions, the conventional PID control and fuzzy PI-Smith control strategies are compared, and the system response is shown in Fig.6 and Fig. 7.

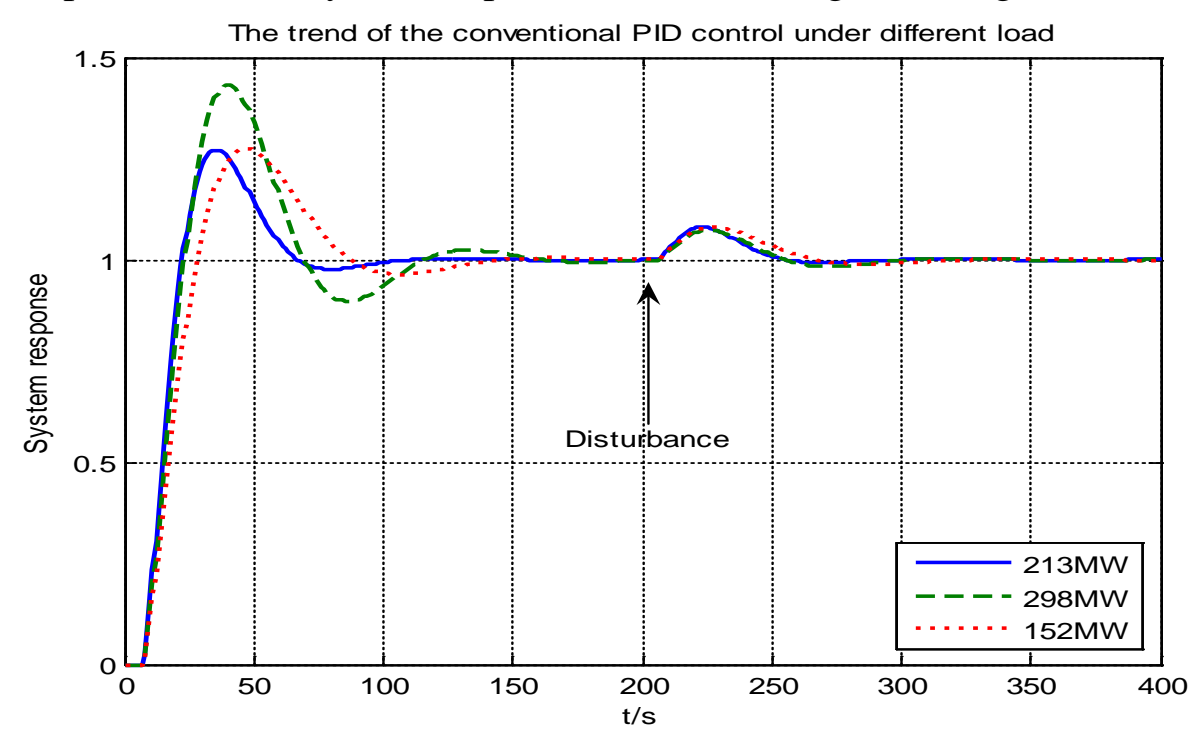

Fig. 6 response curves of conventional PID control system under different loads 


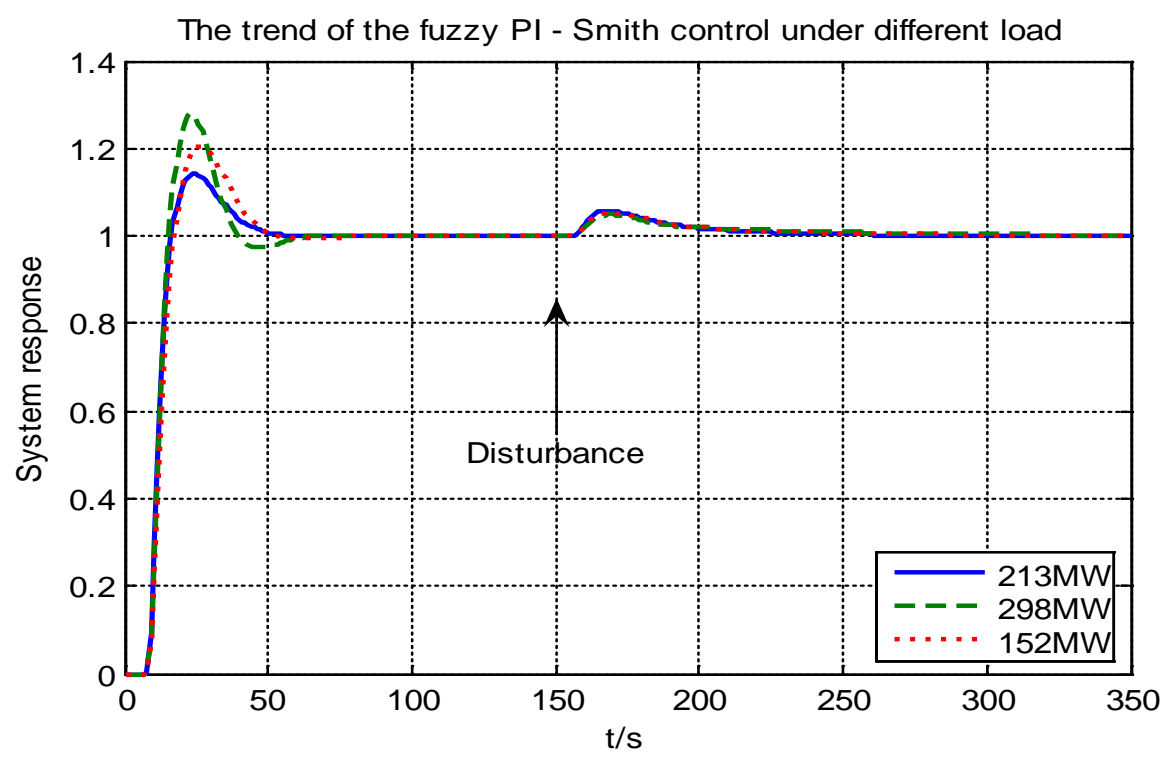

Fig. 7 response curves of fuzzy PI-Smith control system under different loads

The fuzzy PI-Smith control has better adaptability and robustness than the conventional PID control under different loads through the comparison of Fig.6 and Fig.7. In Fig.6, under the control of conventional PID, the system gradually increases with the decrease of load, the response time is gradually increased, and the overshoot of the system decreases gradually with the increase of the load. The response time decreases gradually.

\section{Summary}

Based in a certain power plant in Shanxi Province "unity of three towers " indirect air cooling system, according to the operation data of power plant, the establishment of a back pressure turbine control simulation model, we apply fuzzy PI Smith predictive compensation control strategy of simulation research. By comparing with the conventional PID control, we can get that the control strategy of fuzzy PI-Smith predictor has obvious advantages, and the robustness of the system is better, and better control effect is obtained.

\section{References}

[1] Zhang Chunyu, Yan Junjie, Lin Wanchao. Theoretical study on the characteristics of Heller type indirect air cooling system [J]. Journal of engineering thermal physics. In volume 25, 1, 2004.1.

[2] Zheng Bo, Meng Xiangru, Li Huan, Ma Haiyuan. Based on Smith forecast research of fuzzy PID active queue management algorithm [J]. Computer engineering and design. (2010).

[3] Jiao Chuanbao, Qu YueJin. YangChengPower plant $600 \mathrm{mw}$ indirect air cooling system design and application [J]. Shanxi electric power. (2012).

[4] Tian Yazhao, Chen Xiaofeng. Direct air cooling system was compared with the heller type indirect air cooling system [B]. North China electric power technology. (2006).

[5] Lu Ping, Zhao Jie, Guo Peng. Based on fuzzy PI modified Smith prediction control and application [J]. Manufacturing automation. (2011).

[6] Chen Lijun, Xu Chao, Millie Jun. Under the new situation of direct and indirect air cooling (J). The analysis of the development of power system engineering, (2010). 